\title{
Vergence Neurons Identified in the Rostral Superior Colliculus Code Smooth Eye Movements in 3D Space
}

\author{
Marion R. Van Horn, ${ }^{1}$ David M. Waitzman, ${ }^{2}$ and Kathleen E. Cullen ${ }^{1}$ \\ ${ }^{1}$ McGill University, Montreal, Quebec H3A 0G4, Canada, and ${ }^{2}$ University of Connecticut Health Center, Farmington, Connecticut 06030
}

The rostral superior colliculus (rSC) encodes position errors for multiple types of eye movements, including microsaccades, small saccades, smooth pursuit, and fixation. Here we address whether the rSC contributes to the development of neural signals that are suitable for controlling vergence eye movements. We use both single-unit recording and microstimulation techniques in monkey to answer this question. We found that vergence eye movements can be evoked using microstimulation in the rSC. Moreover, among the previously described neurons in rSC, we recorded a novel population of neurons that either increased (i.e., convergence neurons) or decreased (i.e., divergence neurons) their activity during vergence eye movements. In particular, these neurons dynamically encoded changes in vergence angle during vergence tracking, fixation in 3D space and the slow binocular realignment that occurs after disconjugate saccades, but were completely unresponsive during conjugate or the rapid component of disconjugate saccades (i.e., fast vergence) and conjugate smooth pursuit. Together, our microstimulation and single-neuron results suggest that the SC plays a role in the generation of signals required to precisely align the eyes toward targets in 3D space. We propose that accurate maintenance of 3D eye position, critical for the perception of stereopsis, may be mediated via the rSC.

\section{Introduction}

The superior colliculus (SC) plays an essential role in the sensorymotor mechanisms that underlie eye movements. When gaze is shifted to an object of interest, neural activity across the SC encodes the distance between the current eye position and the final goal. At the rostral tip of the SC, neuronal activity represents small position errors for multiple eye movement types, including microsaccades, small saccades, smooth pursuit, and fixation (Munoz and Wurtz, 1993; Krauzlis et al., 1997; Bergeron and Guitton, 2000; Choi and Guitton, 2006; Hafed and Krauzlis, 2008; Hafed et al., 2009). These previous studies have focused on the commands produced by the SC during conjugate eye movements, yet during normal viewing conditions we typically look between objects located at different depths and eccentricities. Despite the fact that the SC is considered one of the most thoroughly studied structures in the primate brain, an examination of motor responses of SC neurons during 3D viewing is virtually nonexistent.

There is mounting evidence to suggest that the SC could play a critical role in the neural control of vergence eye movements. This area receives inputs from disparity-sensitive cortical and subcortical regions (Gnadt and Mays, 1995; Gnadt and Beyer, 1998; Ferraina et al., 2000; Genovesio and Ferraina, 2004; Mime-

\footnotetext{
Received May 9, 2012; revised March 3, 2013; accepted March 16, 2013.

Author contributions: M.R.V.H., D.M.W., and K.E.C. designed research; M.R.V.H., D.M.W., and K.E.C. performed research; M.R.V.H. and K.E.C. analyzed data; M.R.V.H., D.M.W., and K.E.C. wrote the paper.

This work was supported by the Natural Science and Engineering Research Council of Canada and the Fonds de la Recherche en Santé du Québec. We thank M. Jamali, D. Mitchell, J. Carriot, and A. Dale for critically reading the manuscript and S. Nuara and W. Kucharski for excellent technical assistance.

The authors declare no competing financial interests.

Correspondence should be addressed to Dr. Kathleen E. Cullen, McGill University, McIntyre Medical Research Building, Room 1219, 3655 Promenade Sir William Osler, Montreal, Quebec H3G 1Y6, Canada. E-mail: kathleen.cullen@mcgill.ca.

DOI:10.1523/JNEUROSCI.2268-12.2013

Copyright $\odot 2013$ the authors $\quad 0270-6474 / 13 / 337274-11 \$ 15.00 / 0$
}

ault et al., 2004) and provides strong descending projections to premotor neurons, which encode vergence-related information (Scudder et al., 1996; Ohtsuka and Nagasaka, 1999; for review, see Cullen and Van Horn, 2011). Microstimulation of the rostral SC (rSC) in the cat has been shown to evoke convergence eye movements (Suzuki et al., 2004), and bilateral lesions of the rSC in humans have been reported to result in convergence palsy (Ohtsuka et al., 2002). Surprisingly, the only study to have examined the relationship of neurons in the SC during $3 \mathrm{D}$ viewing focused on neurons in the intermediate and deep layers of the caudal SC. That study concluded that shifts in the movement fields were most consistent with a role in conjugate saccade control and were not appropriate for driving vergence eye movements (Walton and Mays, 2003). Notably, no studies have explored whether the rSC is involved in realigning gaze between near and far targets.

Thus, the goal of the current study was to establish whether neurons in the rSC contribute to the development of the neural command signals required to control eye movements in $3 \mathrm{D}$ space, or whether their discharge strictly controls only the conjugate component of eye motion. To answer this question, we used both single-unit recording and microstimulation techniques. For the first time, we describe a distinct group of neurons within the rSC that are unresponsive during traditional conjugate eye movement paradigms but are significantly modulated during smooth vergence tracking and 3D fixation as well as the binocular realignment that follows saccades made in 3D space. Our results expand the functional role of the SC to include alignment of the eyes in $3 \mathrm{D}$ space, thereby ensuring accurate stereopsis.

\section{Materials and Methods}

Surgical procedures

Two female rhesus monkeys (Macaca mulatta) were prepared for chronic extracellular recordings using the aseptic surgical procedures described previously (Sylvestre and Cullen, 1999). Briefly, a stainless-steel post was 
attached to the animal's skull with stainless-steel screws and dental acrylic, permitting complete immobilization of the animal's head. Two stainless-steel recording chambers were also secured to the implant. In one monkey, the recording chambers were oriented stereotaxically toward the oculomotor nucleus on the right and left side of the brainstem. In the second monkey, the recording chamber was tilted backward by 37 degrees and centered over the SC. To record binocular eye position, a coil (three loops of Teflon-coated stainless-steel wire, 18-20 mm diameter) was implanted in each eye (Judge et al., 1980). All procedures were approved by the McGill University Animal Care Committee and University of Connecticut Health Center and complied with the guidelines of the Canadian Council on Animal Care and NIH.

\section{Behavioral paradigms}

Monkeys were trained to fixate targets for a juice reward. The timing and location of target illumination, data acquisition, and online data displays were controlled using REX, a UNIX-based real-time acquisition system (Hayes et al., 1982).

\section{Conjugate paradigms}

To elicit conjugate movements, a red $\mathrm{HeNe}$ laser target was projected onto a cylindrical screen located $55 \mathrm{~cm}$ away from the monkey's eyes. To characterize a neuron's preferred direction, horizontally and vertically directed conjugate saccades were elicited by stepping the laser target between positions ( $\pm 5-30$ degrees), in 5 degree increments, in predictable and unpredictable sequences, and oblique saccades were generated by stepping the laser target between a central target to a sequence of targets that had varying vertical and horizontal components within this same range. Fixational intervals were obtained by keeping the target stationary for a random duration of 1-3 s. A blink paradigm was also used to test whether a neuron showed visual sensitivity. Briefly, while the monkey maintained fixation on a visual target, the target was "blinked" off for 100-500 ms. The monkey was required to maintain stable fixation before, during, and after the blink period to receive a juice reward. A neuron was considered to have a visual response if the neuronal firing rate decreased to $<5$ spikes/s during the blink period (Munoz and Wurtz, 1993). Horizontal and vertical conjugate smooth pursuit eye movements were generated by moving the laser target sinusoidally (20 degrees/s peak velocity, $0.4 \mathrm{~Hz}$ ).

\section{Vergence paradigms}

Changes in vergence angle were elicited using a planar array of red light emitting diodes (LEDs), with intensities comparable with that of the laser target, which was positioned between the screen and the monkey. Symmetric vergence was elicited by sequentially illuminating LEDs located along the midline (convergence angles: 17, 12, 8, and 6 degrees). Fixational intervals were obtained by keeping the target stationary for 1-3 s. Disconjugate saccades were generated by stepping the target from one of the LEDs to an eccentric laser target position on the screen. This approach yielded a rich variety of disconjugate saccades. Monkeys were also trained during a vergence smooth pursuit task where the laser target was projected onto a horizontal board positioned at eye level, between the screen and the monkey. The laser target moved sinusoidally at the same frequency and velocity used during conjugate smooth pursuit (20 degrees/s peak velocity, $0.4 \mathrm{~Hz}$ ).

\section{Data acquisition procedures}

During experiments, monkeys were seated in a primate chair located within the center of a $1 \mathrm{~m}^{3}$, magnetic eye coil system (CNC Engineering). Horizontal and vertical eye position signals were measured using the magnetic search coil technique (Fuchs and Robinson, 1966; Judge et al., 1980). Each eye coil signal was calibrated independently by having the monkey fixate, with one eye masked, a variety of targets at different horizontal and vertical eccentricities and different depths. Position signals were low-pass filtered at $250 \mathrm{~Hz}$ (analog 8 pole Bessel filter) and sampled at $1 \mathrm{kHz}$. Because ocular saccades include very little power $>50$ $\mathrm{Hz}$ (Zuber et al., 1968; Van Opstal et al., 1985; Cullen et al., 1996), eye position signals were further digitally filtered (with a 51st order finiteimpulse-response filter with a Hamming window and a cutoff at $125 \mathrm{~Hz}$ ), before being differentiated to obtain eye velocity signals (using zerophase forward and reverse digital filtering to prevent phase distortion).

\section{Microstimulation}

In both monkeys, the topographic map of the SC was initially determined using microstimulation. This approach permitted identification of the rostral zone of the SC. Saccades were elicited using stimulation parameters, which have been previously used to reliably evoke saccadic eye movements (15-50 $\mathrm{A}$, $333 \mathrm{~Hz}, 200-500 \mathrm{~ms}$ ) (Freedman et al., 1996; Melis and van Gisbergen, 1996; Stanford et al., 1996; Gandhi and Keller, 1999; Paul and Gnadt, 2006). A stimulation threshold was determined at each site by gradually increasing the current strength. The stimulation threshold was defined as the current strength where at least $75 \%$ of all stimulation trials led to a saccadic response while the monkey fixated a far target. To ensure a reliable response during experiments, we used twice the stimulation threshold. For each stimulation, the latency from the onset of stimulation and the onset of the first saccade and first vergence eye movement was calculated. Both saccade and vergence onset were, respectively, defined as the time at which conjugate and vergence velocity was $>10$ degrees/s. Once we had mapped out the rostral pole of the SC and identified the area where stimulation evoked horizontal saccades $<5$ degrees, we then began our recordings in this area. To minimize potential stimulation-induced damage stimulation, stimulation was then limited so as to ensure that we could record for as long as possible.

\section{Extracellular single-unit recordings}

Extracellular single-unit activity was recorded using enamel insulated tungsten microelectrodes (2-10 M $\Omega$ impedance, Frederick Haer; for details, see Sylvestre and Cullen, 1999). The topographic map of the SC was determined by calculating the "preferred" saccade amplitude and direction of neurons encountered in the intermediate layers of the SC. When a neuron was isolated, unit activity, horizontal and vertical positions of the right and left eyes, and target position were recorded on a digital audio tape. The isolation of each neuron was reassessed offline during playback. A neuron was considered to be adequately isolated only when individual action potential waveforms could be discriminated using a windowing circuit (BAK) during saccades (e.g., Sylvestre and Cullen, 1999, their Fig. 1) and during fixation. Subsequent analysis was performed using custom algorithms (Matlab, The MathWorks).

A number of criteria were used to verify that neural recordings were made in horizontal meridian of the intermediate/deep layers of the rSC. First, we restricted our recordings to areas where microstimulation resulted in horizontal staircase saccades $<5$ degrees. Second, upon entering the $\mathrm{rSC}$, we recorded visual neurons that were tonically active during the fixation of a central visual target but whose neural activity decreased when the target was momentarily blinked off. Third, at sites adjacent to the ones where we recorded our novel population of vergence neurons, we also indentified rSC burst neurons and fixation neurons with the same neuronal characteristics as have been previously described (Hafed et al., 2009). Neuronal recordings were focused in areas in the rSC for which bursting neurons were best tuned for small horizontal saccades and increased activity during contralateral smooth pursuit (see Fig. 3B).

\section{Data analysis}

Definitions and conventions. Eye movements are described in terms of conjugate $[$ conjugate $=($ left eye + right eye $) / 2]$ and vergence $[$ vergence $=$ left eye - right eye] coordinates (where the left eye and right eye inputs could be either position or velocity signals), such that positive and negative vergence velocity signals denote convergence and divergence, respectively. In addition, we report the movement of each eye as either ipsilateral or contralateral based on their location relative to the recording site. Positive and negative values indicate eye positions that are to the right and left, or up and down of the central position (i.e., straight ahead), respectively.

Metric analysis. A neuron's vergence position sensitivity was measured as the slope of the relationship between the mean vergence position and the mean firing rate measured during fixation. Periods of fixation were defined as time intervals $\geq 200 \mathrm{~ms}$ during which peak conjugate and vergence velocities were $<5$ degrees/s.

Dynamic analysis. The linear optimization techniques used to quantify the dynamic sensitivity of a neuron to eye movements have been described in detail previously (Cullen et al., 1996; Sylvestre and Cullen, 
1999). The spike train was convolved with a Kaiser window to obtain a measure of the neuronal firing rate (Cherif et al., 2008). Briefly, during vergence tracking, the firing rate of each neuron was estimated using a simple linear model:

$$
F R(t)=b+k V G(t)+r \dot{V} G(t)
$$

where $\mathrm{FR}$ is the instantaneous firing rate and $b, k$, and $r$ are constants that represent a bias, the estimated position sensitivity, and estimated velocity sensitivity, respectively. VG and VG refer to instantaneous vergence position and velocity during vergence tracking. Model parameters estimated during vergence tracking were subsequently used to predict the firing rate during disconjugate saccades. Notably, each neuron's eye velocity sensitivity was corrected for a time delay that was estimated based on stimulation and neuronal response (e.g., $20 \mathrm{~ms}$ ). In particular, a $20 \mathrm{~ms}$ latency accounted for $\sim 3$ degrees of the average 9 degree lead observed in the $0.4 \mathrm{~Hz}$ tracking data; thus, velocity sensitivities were reduced by a factor of 3/9 (i.e., 1/3).

The goodness of fit of the data to each model was quantified using the Variance-Accounted-For $(\mathrm{VAF}=1-[\operatorname{var}(\bmod -\mathrm{fr}) / \mathrm{var}(\mathrm{fr})]$, where mod represents the modeled firing rate and fr represents the actual firing rate). The VAF in linear models is equivalent to the square of the correlation coefficient $\left(R^{2}\right)$, such that a model with a VAF of 0.64 provides as good a fit to the data as a linear regression analysis that yields a correlation coefficient of 0.80 (Cullen et al., 1996).

Histology. Histology, done in one monkey, confirmed that penetrations were in the rostral pole of the left SC.

Statistical analysis. Unless specifically stated otherwise, data presented in the results are described as mean \pm SD. A Student's $t$ test was used to determine whether the average of two measured parameters differed significantly from each other.

\section{Results}

Overview

In this study, we used microstimulation and single-unit recording techniques to determine the role the rSC plays in generating vergence eye movements. Experiments were performed in 2 monkeys and focused on the region of the rSC for which microstimulation elicited small staircase saccades (Fig. $1 A$ ). We found that vergence eye movements can be evoked using microstimulation in the rSC with latencies comparable to saccades. Further, a thorough examination of the response properties of neurons in the rSC revealed a unique population of vergence neurons involved in reorienting gaze between near and far viewing. Reconstructions of the recording tracks suggest that vergence neurons are typically found $\sim 1.5-3.5 \mathrm{~mm}$ below parafoveal visual neurons and are uniformly distributed among neurons that respond to fixation, small saccades, and contralateral smooth pursuit (Fig. 1A).

\section{Microstimulation: vergence initiated at the onset of small staircase saccades}

Microstimulation of the $\mathrm{rSC}(N=21)$ elicited very small $(<5$ degrees, Fig. $1 B$ ), conjugate staircase saccades when the monkey fixated a far target (Fig. $1 C$, top). A very striking, and reproducible result was observed when the same microstimulation parameters were used while the monkey fixated a near target. Specifically, if microstimulation occurred when the eyes were initially converged, the resulting series of staircase saccades was also accompanied by a series of diverging eye movements, which was sustained throughout the duration of the stimulation (Fig. $1 C$, NEAR; bottom). The average sizes of the conjugate and vergence component of the first step were $1.7 \pm 0.9$ degrees and $0.53 \pm 0.3$ degrees, respectively. This resulted in a cumulative change of $4.1 \pm 2.9$ degrees and $2.2 \pm 1.1$ degrees, respectively, after $200 \mathrm{~ms}$ of stimulation when the monkey was fixating a near target (Fig. 1D). Notably, the vergence velocities, like conjugate velocities, evoked by microstimulation followed the main sequence $\left(R^{2}=0.68\right.$; slope $\left.=18.6\right)$ and were comparable with those previously reported during voluntarily produced vergence movements in monkeys (Busettini and Mays, 2005).

For each microstimulation site, the latency from the onset of microstimulation and the onset of either the first saccade or vergence eye movement was calculated. Figure $1 E$ plots the distribution of latencies during far (left panel) and near (right panel) viewing. During far and near viewing, the average latency from the onset of microstimulation and the onset of the first saccade were not significantly different $(22.5 \pm 6.1 \mathrm{~ms}$ and $21.9 \pm 6.7 \mathrm{~ms}$, respectively; $p>0.05$; Fig. $1 E$, black bars). Moreover, during near viewing, the onset of vergence (Fig. $1 E$, right panel, red bars) was not significantly different from the onset of the first saccade $(21.9 \pm 6.7$ vs $20.63 \pm 5.3 \mathrm{~ms} ; p>0.05)$ and was linearly related to conjugate latency (Fig. $1 F$ ). The short latency of vergence as well as saccadic movements, combined with the strong temporal coupling of their onset, suggests that both components of each eye's movement were evoked by the microstimulation.

In addition to finding that we could evoke diverging eye movements, we also identified a smaller number of sites $(N=3)$ in one monkey where the same stimulation parameters elicited small staircase saccades that were accompanied by small converging eye movements (Fig. 2A). Converging eye movements could be evoked when the monkey looked far or near and the size of convergence movement ranged from 0.28 to 1.2 degrees (average, $0.83 \pm 0.37$ degrees) and the average size of the conjugate component of the movement ranged from 0.93 to 4.3 degrees (average, $2.2 \pm 1.1$ degrees). In general, the average latency to the onset of the convergence eye movement was slightly longer than the latency to evoke divergence $(47.2 \pm 10.4 \mathrm{~ms}$ ) (Fig. 2C). These data are in agreement with previously published data in the cat that has also shown that stimulation of the rSC can elicit converging eye movements of similar size and latencies.

\section{Single-unit recording: identification of divergence and convergence neurons in the rSC}

Neural recordings were subsequently made in regions in the rSC at the same sites where microstimulation elicited staircase saccades $<5$ degrees and vergence eye movements. Notably, upon entering the rSC, we recorded visual neurons that were tonically active during the fixation of a central visual target (Fig. $3 A$ ) and decreased their activity when the visual target was momentarily turned off (i.e., neurons with parafoveal visual fields) (Goldberg and Wurtz, 1972). Second, below the visual neurons, we identified neurons that discharged for very small conjugate motor errors during pursuit and/or fixation, as has been described previously (Munoz and Wurtz, 1993; Krauzlis et al., 2000; Hafed and Krauzlis, 2008; Hafed et al., 2009; Reyes-Puerta et al., 2010). An example neuron that increased its activity during small, contralateral saccades and pursuit is illustrated in Figure $3 B$. Interestingly, in the same vicinity as the rSC burst neurons, we identified a unique population of tonic firing neurons that were completely unresponsive during visual fixation tasks as well as during conjugate saccadic eye movements and conjugate smooth pursuit $\left(N_{\text {total }}=19: N_{\text {monkeys }}=11, N_{\text {monkeyD }}=8\right)$. An example from this population of neurons, recorded during a visual fixation task, as well as during small contralateral saccades and conjugate contralateral smooth pursuit, is illustrated in Figure $3 C$.

Notably, in contrast to the other neuron classes we encountered in the $\mathrm{rSC}$, the activity of these tonic firing neurons was clearly modulated when the monkey looked from a far target to a 
A

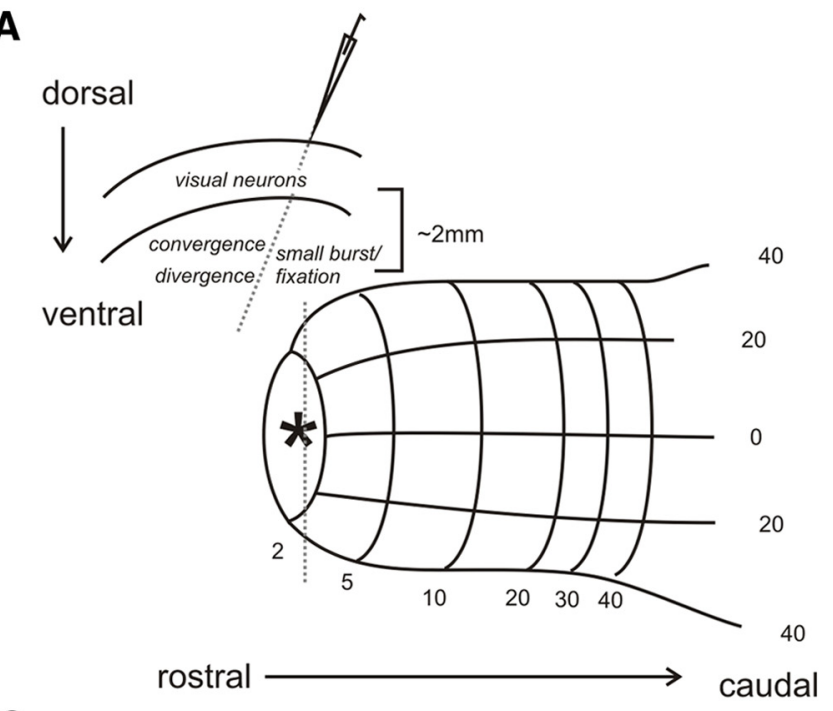

C

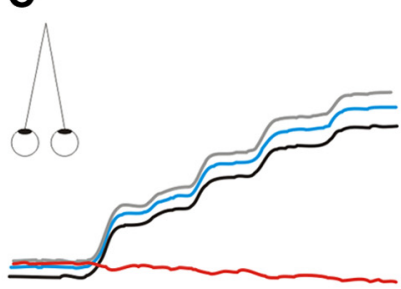

FAR
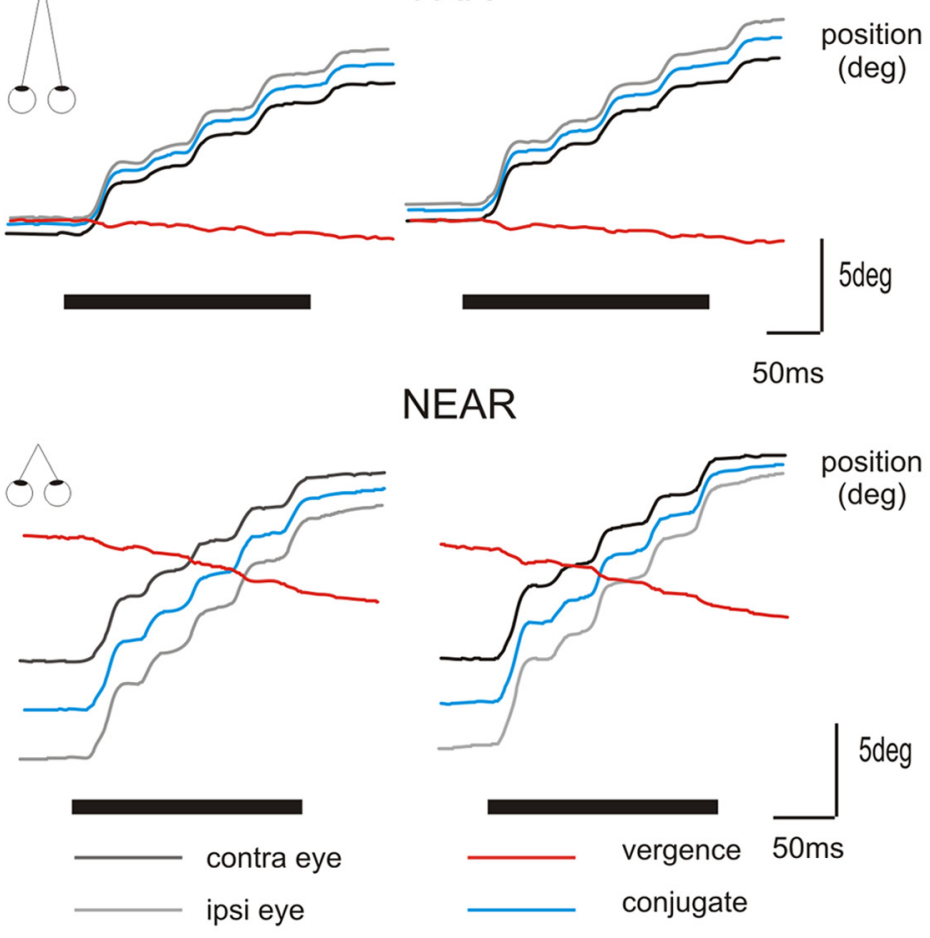

$\mathbf{E}$

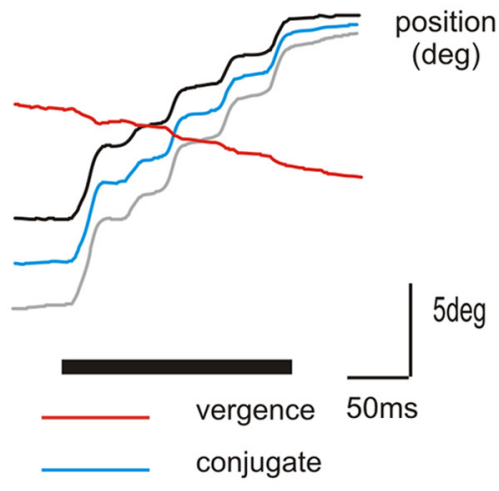

FAR

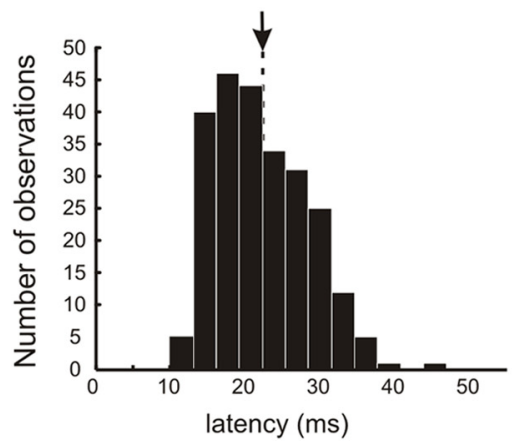

B

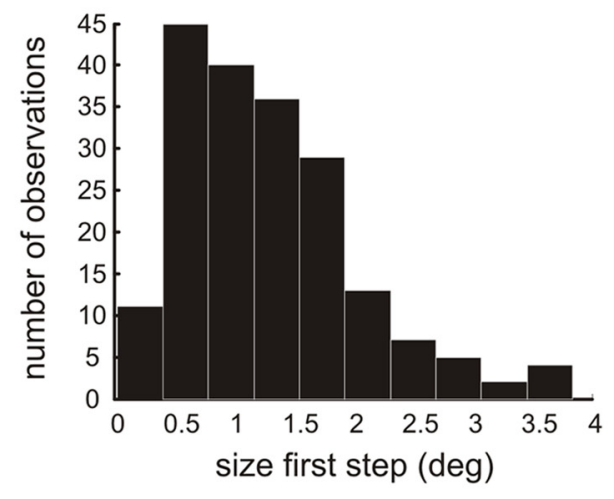

D
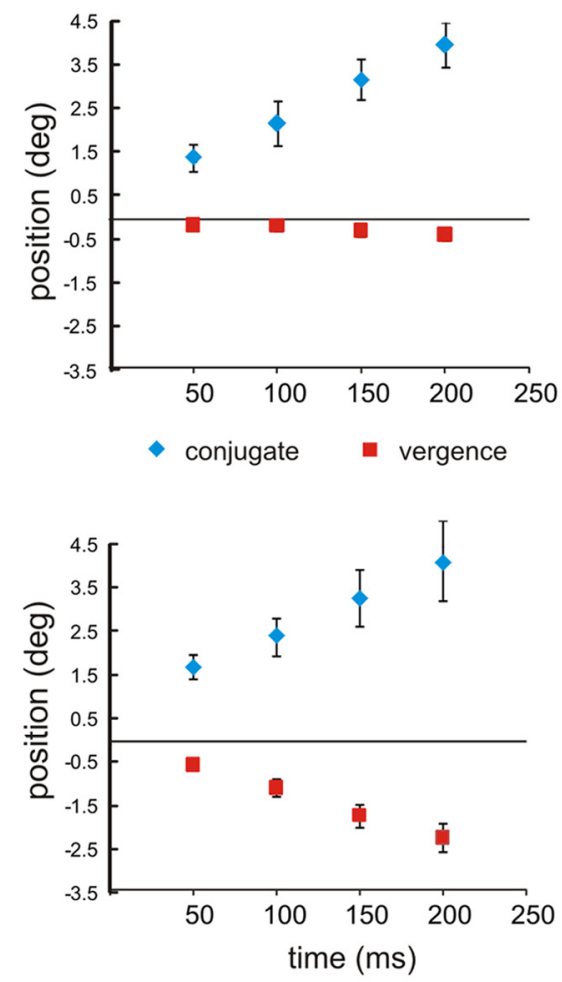

$\mathbf{F}$

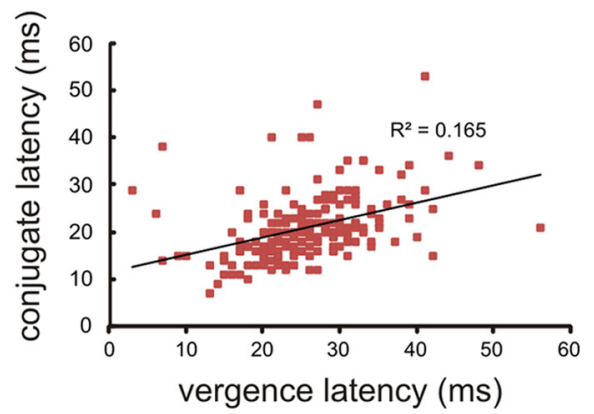

Figure 1. Example of vergence eye movements evoked by electrical stimulation of the rSC. A, Schematic representation of the topographic map of the SC. *The location an example site of stimulation in the rSC that evoked vergence eye movements. Inset, Dorsal/ventral location of vergence compared with rSC visual neurons and small motor burst neurons. (Figure legend continues.) 
near target (i.e., during convergence). For instance, as shown in Figure $4 A$, the example neuron's response decreased as a function of increasing vergence angle, such that it was completely silent when the monkey fixated a very near target (Fig. 4A1). Quantification of this relationship showed that neural discharge decreased linearly as a function of increasing convergence angle (Fig. 4A2; slope $=-3.7 ; r=-0.79$ ). Because the activity of this neuron was higher when the eyes were diverged, we refer to this neuron as a "divergence" neuron.

In addition to identifying divergence neurons, we also recorded neurons that increased their activity during converging eye movements. Figure $4 B 1$ illustrates one example neuron. Remarkably, the neuron was virtually silent while the monkey looked at a distant target, suggesting that previous studies, which identified neurons in the rSC during tasks that required only far viewing, would not have identified these neurons. It was not until the monkey looked to a near target that the neuron began to discharge. A linear regression of the neural response plotted against vergence angle shows that this neuron's activity was linearly related to vergence angle (Fig. $4 B 2$; slope $=2.7 ; r=0.66$ ). In contrast, a linear regression between conjugate position and firing rate confirmed that the neuron was unrelated to changes in conjugate position (data not shown; $r=0.07$ ). Because the activity of this neuron was higher during convergence, we refer to it as a "convergence" neuron.

Overall, we identified a population of divergence and convergence neurons with responses that were linearly related to vergence angle. Regression lines for each neuron in the population is shown in Figure 4A2, B2 (divergence: $N_{\text {total }}=8$, mean divergence vergence slope $=-2.5 \pm 1.03$, mean $r=-0.71 \pm 0.17$; convergence: $N_{\text {total }}=11$, mean convergence vergence slope $=3.2 \pm 2.3$; mean $r=0.61 \pm 0.25)$ but were unrelated to changes in conjugate position (divergence: mean conjugate slope $=-0.19 \pm 0.8$; convergence: mean conjugate slope $=-0.3 \pm 6.7$; Fig. $4 A 2, B 2$, insets). Notably, convergence and divergence neurons could be recorded within a few hundred micrometers from each other, on the same recording track.

\section{Neurons in rSC dynamically encode vergence during vergence tracking}

We further tested the responses of diverging and converging neurons during a number of tracking paradigms. We found that, when the monkey pursued a distant target (i.e., conjugate pursuit), both neuron types were unresponsive (Fig. 5A). However, during sinusoidal smooth tracking of a target indepth (i.e., vergence pursuit), neurons were clearly modulated (Fig. $5 B$ ). In particular, as illustrated in Figure 5B1, the firing rate of a divergence neuron (Fig. $5 B 1$; the same example neuron shown in Fig. $4 A$ ) decreased as the eyes tracked an ap-

\section{$\leftarrow$}

(Figure legend continued.) $\quad \boldsymbol{B}$, Distribution of the size of the first saccade evoked by stimulation in the $\mathrm{ISC}\left(N_{\text {Monkeys }}=105, N_{\text {MonkeyD }}=89\right)$. C, Two examples of a series of staircase saccades evoked by stimulation (dark bar) during fixation of a far (top) and near (bottom) target. Stimulation during fixation of a far target evoked very small conjugate staircase saccades with no change in vergence angle. Conversely, stimulation during fixation of a near target (convergence $\sim 10$ degrees) evoked small staircase saccades with a significant diverging eye movement. $\boldsymbol{D}$, Average change in conjugate and vergence position over time during far (top) and near (bottom) viewing for all stimulation sites. $\boldsymbol{E}$, Distribution of latencies calculated from the onset of stimulation to the onset of either a conjugate saccade (black bars) or the vergence movement (red bars) during far (left) and near (right) viewing. $\boldsymbol{F}$, Regression between vergence latency and conjugate latency calculated during near viewing. contra, Contralateral eye; ipsi, ipsilateral eye position. proaching target (i.e., during convergence). In contrast, the firing rate of a convergence neuron (Fig. 5B2; same neuron as in Fig. $4 B$ ) increased as the eyes tracked the approaching target. We found that we could estimate the firing rate of each neuron using a simple linear model:

$$
F R(t)=k V G(t)+r \dot{V} G(t)
$$

where $\mathrm{FR}$ is the instantaneous firing rate and $b, k$ and $r$ are constants that represent a bias, the estimated position sensitivity, and estimated velocity sensitivity, respectively. VG and $\dot{V} G$ refer to instantaneous vergence position and velocity during vergence tracking. Average model fits (in blue) are superimposed on the firing rates (black) for the two example neurons shown in Figure $5 B$. For our population of neurons, this model closely fit discharge modulation during vergence pursuit $\left(\mathrm{VAF}_{\text {diverg }}=0.42 \pm 0.27, \mathrm{VAF}_{\text {converg }}=0.3 \pm 0.11\right)$. Conversely, a model in which conjugate parameters used as the model input fit the discharge pattern poorly $\left(\mathrm{VAF}_{\text {diverg }}=\right.$ $0.01 \pm 0.02, \mathrm{VAF}_{\text {converg }}=0.02 \pm 0.02$ ). Notably, a comparison of the bias and vergence position sensitivities estimated during vergence pursuit were comparable with those estimated using the linear regression during fixation. This result further suggests a tight linkage between neuronal responses and motor output during disconjugate eye movements.

\section{Convergence and divergence neurons in the rSC encode slow but not fast vergence}

We have shown that vergence neurons in the rSC dynamically encode slow changes in vergence during slow smooth pursuit of a target in-depth, as well as static changes in vergence angle. We next analyzed whether these same vergence neurons might play a role in commanding eye motion when gaze is rapidly redirected between near and far targets. Notably, 3D reorienting eye movements are typically characterized by a period of fast saccadic vergence, which quickly redirects the eyes by unequal amounts (i.e., disconjugate saccade), in addition to periods of initial and/or late slow vergence, which are needed to binocularly position the two eyes and ensure stereopsis (e.g., see Fig. 6A). Previous studies have shown that neurons within the brainstem saccadic network (e.g., saccadic burst neurons in the PPRF) dynamically encode the movement of an individual eye during disconjugate saccades but are unresponsive during initial and late periods of slow vergence (King and Zhou, 2002; Van Horn et al., 2008; Cullen and Van Horn, 2011). Accordingly, this has left open the important question of where the signals guiding slow vergence arise. Consistent with the above recording results, the activity of divergence and convergence neurons in the $\mathrm{rSC}$ was appropriate for driving the slow vergence after a disconjugate saccade.

A typical sequence of neuronal activity for a convergence neuron is illustrated in Figure $6 \mathrm{~B}$. We first aligned neuronal activity on the onset of the disconjugate saccade (e.g., fast vergence onset, left panel) and found that the onset of spikes occurred after the onset of fast vergence (Fig. $6 \mathrm{~B}$, left). However, when spiking activity was aligned on slow vergence (Fig. $6 B$, right), we found that the onset of neural activity was tightly linked with onset of slow vergence (Fig. $6 B$, right). Calculating the latency to the first spike (e.g., response activation) revealed that the response activation was more correlated with the onset of slow vergence $\left(R^{2}=0.76\right.$; Fig. $6 C$, left) compared with the onset of fast vergence $\left(R^{2}=0.33\right)$. Overall, for the population of converging and diverging neurons, response activation showed a stronger correlation with the onset of slow vergence $\left(R^{2}=0.70 \pm 0.15\right.$ and $R^{2}=0.76 \pm 0.17$, 
A

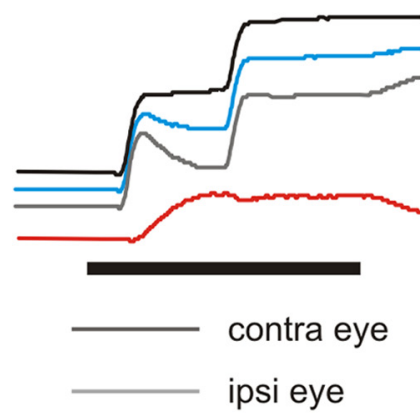

B

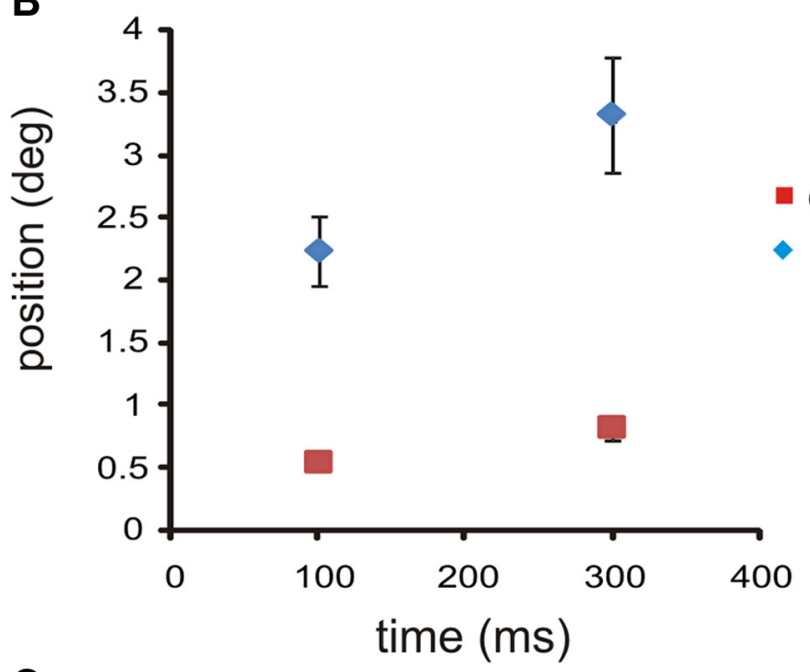

C

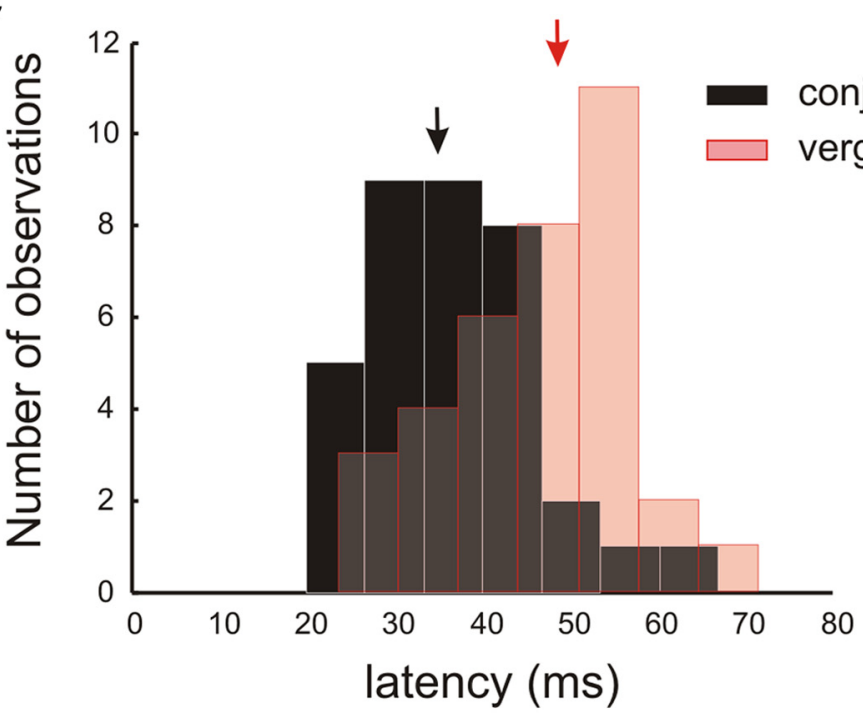

Figure 2. Example of convergence eye movements evoked by electrical stimulation of the rSC. A, Two examples of a series of staircase saccades evoked by stimulation (dark bar) during far fixation that evoked very small conjugate staircase saccades with a significant converging eye movement. $\boldsymbol{B}$, Average change in conjugate and vergence position over time. $\boldsymbol{C}$, Distribution of latencies calculated from the onset of stimulation to the onset of either a conjugate saccade (black bars) or the vergence movement (red bars).

respectively) compared with fast vergence $(0.29 \pm 0.24$ and $0.20 \pm 0.24$, respectively). Furthermore, calculating the latency from the onset of slow vergence to the time of response activation revealed that it was shorter and less variable than the latency calculated from the onset of the saccade and the time of response activation ( $17.0 \pm 17.9$ vs $66.5 \pm 33.1$; Fig. $6 C$, right), suggesting that vergence responses were more tightly linked to the onset of slow vergence than fast vergence.

We next performed a quantitative analysis of neuronal discharge dynamics during the disconjugate saccades. In particular, we sought to determine whether the sensitivities estimated during slow vergence tracking (e.g., Eq. 1, Fig. 5), which, when corrected for a time delay (see Materials and Methods), could be used to predict a neuron's activity during a disconjugate saccade.

$$
\begin{aligned}
F R(t)=b+ & k V G\left(t-t_{d}\right) \\
+ & r \dot{V} G\left(t-t_{d}\right)
\end{aligned}
$$

Interestingly, the predicted firing rate overestimated the actual neuronal discharge during the fast vergence epoch but was much more accurate at predicting the actual firing rate during the slow component (Fig. 6B). A comparison of the VAF calculated during the fast vergence epoch to VAF calculated during the slow vergence epoch confirmed that this example neuron preferentially encoded the slow component of the disconjugate saccade $\left(\mathrm{VAF}_{\text {fast }}=-1.9 \mathrm{vs} \mathrm{VAF}_{\text {slow }}=0.06\right)$. Similarly, a far better prediction was obtained for the slow component of the movement than for the fast component across the population $\left(\mathrm{VAF}_{\text {fast }}=-1.8 \pm 2 \mathrm{vs} \mathrm{VAF}\right.$ slow $=0.05 \pm 0.1)$. Thus, the discharge of vergence neurons in the rSC not only encoded vergence during pursuit in-depth but also dynamically encoded slow changes in vergence that are suitable for ensuring precise binocular alignment after disconjugate saccades.

\section{Discussion}

Neurons in the rSC have been shown to encode small position errors during conjugate eye movements, including small saccades, smooth pursuit, and fixation (Krauzlis et al., 1997; Bergeron and Guitton, 2000; Choi and Guitton, 2006; Hafed and Krauzlis, 2008). In this study, we extend the functional role of the $\mathrm{rSC}$ and demonstrate that it also plays an essential role in generating vergence eye movements. Using microstimulation, we found that we could elicit vergence eye movements and, using single-unit recording techniques, we identified and characterized a distinct class of neurons that encode vergence angle. These "vergence" neurons were recorded in the intermediate to deep layers of the rSC, below visual neurons, and among the previously described rSC neurons that respond to small position errors during conjugate eye movements. Importantly, identified vergence neurons that were unre- 
A

$$
\begin{aligned}
& \text { visual neuron } \\
& \text { (superficial layer) }
\end{aligned}
$$

target onset

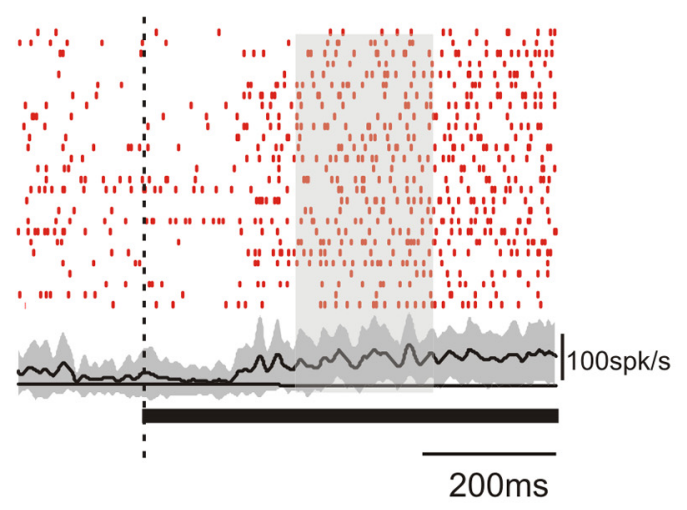

\section{c1 divergence neuron}

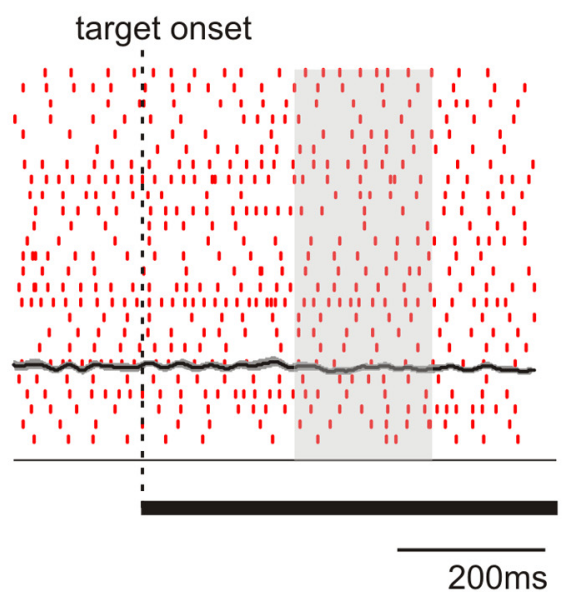

\section{B small motor burst neuron (intermediate layer)}

saccade onset

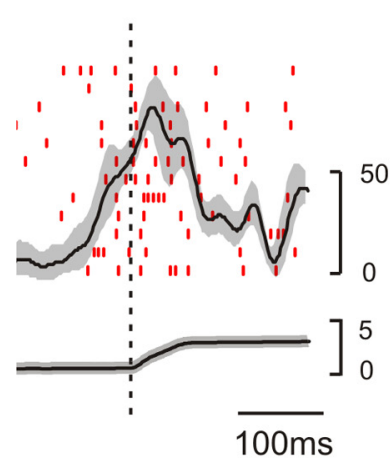

pursuit

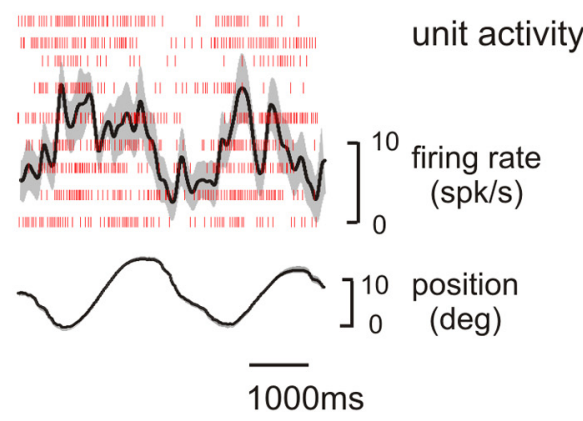

— conj eye position

\section{C2}

\section{divergence neuron}
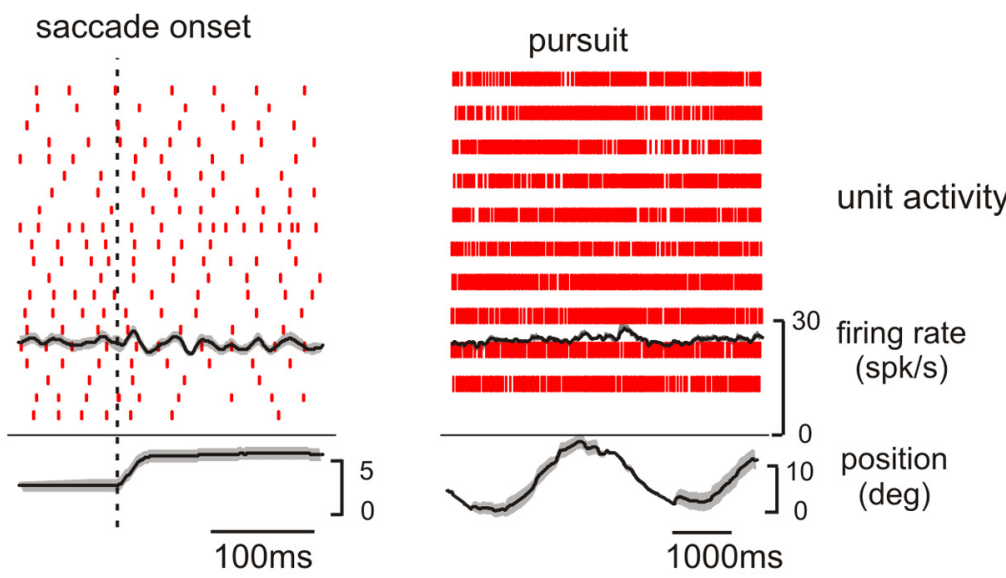

— conj eye position

Figure 3. Example neurons recorded in the rSC. $A$, Example of a typical parafoveal visual neuron recorded during the presentation of a visual target. Raster plots are aligned on target onset. Gray shaded area represents the time segment used to calculate average firing rate after the visual stimulus was presented. $\boldsymbol{B}$, Example discharge of an rSC small motor burst neuron, recorded among the convergence and divergence neurons, during small contralateral saccades and smooth pursuit. Raster plot (left panel) aligned on saccade onset. C, Example raster plots of a divergence neuron during (C1) a visual paradigm and (C2) small conjugate saccades (left) and conjugate smooth pursuit (right). Average firing rate with SEs are superimposed on the unit activity, and average position trace with SEs is plotted below. conj, Conjugate.

sponsive during conjugate movements were found to dynamically encode slow changes in vergence angle during vergence pursuit as well as during slow vergence after $3 \mathrm{D}$ saccades to ensure accurate binocular alignment. Overall, our findings provide important new insight into how the brain controls 3D gaze and support the proposal that distinct neural pathways control fast versus slow vergence.

\section{The rSC and the neural control of vergence}

In the present experiment, we provide strong electrophysiological evidence that the rSC plays an important role in generating and maintaining binocular eye movements. We microstimulated the intermediate/deep layers of the rSC and found that, when the monkey fixated a far fixation point, the resulting eye movements were comprised of a sequence of very small conjugate saccades (i.e., staircase saccades) in the contralateral direction. However, when microstimulation was applied while the eyes were initially converged, diverging disconjugate saccades were evoked. Importantly, the average latency for vergence initiation was comparable to that of saccade initiation (e.g., $\sim 20 \mathrm{~ms}$ ), consistent with saccadic latencies reported in previous microstimulation studies of in the rSC (Gandhi and Keller, 1999). Although far less frequent, we also identified sites where microstimulation resulted in convergence. These data are in agreement with previously published data in the cat, which has also reported that stimulation of the rSC can evoke convergence (Suzuki et al., 2004). Our results are also in agreement with studies in human and monkey that have shown that lesions of the rSC result in impairments in maintaining binocular eye alignment (Lawler and Cowey, 1986; Ohtsuka et al., 2002).

At the same sites that evoked vergence responses, we identified, for the first time, using single-unit recording techniques, a distinct 


\section{DIVERGENCE NEURON}

A1

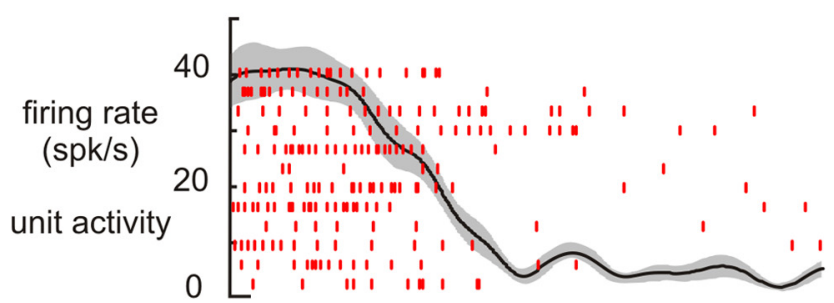

position ${ }^{10}$

(deg)

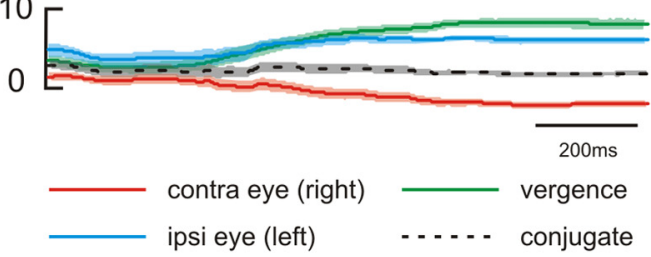

\section{convergence-step}

(1)

B1

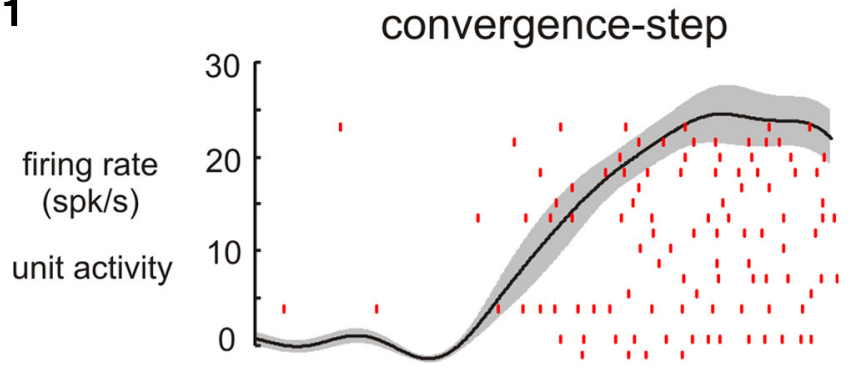

position

(deg)

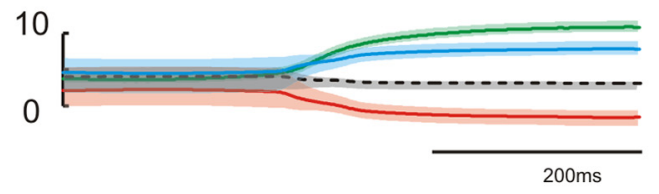

A2

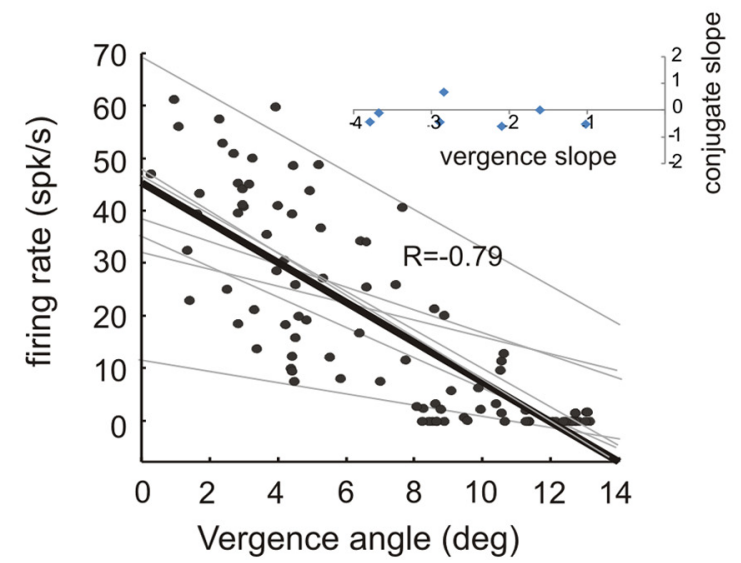

\section{CONVERGENCE NEURON}

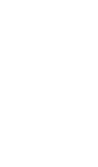

B2

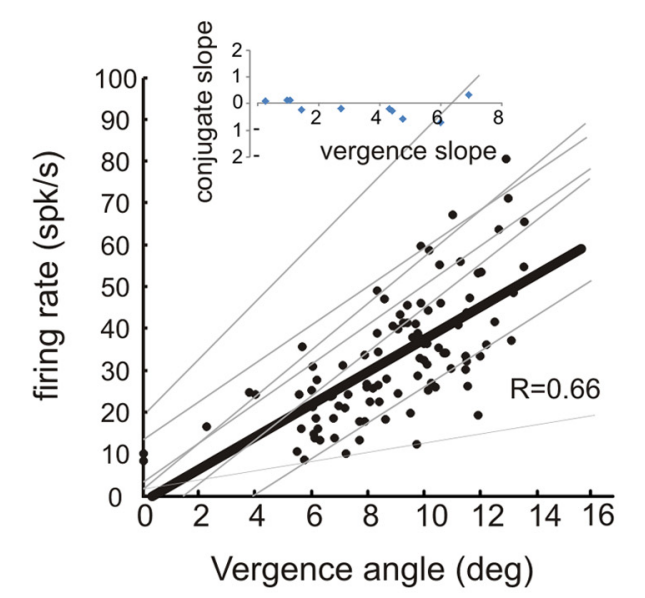

Figure 4. Example vergence neurons in the rSC. A1, Neuronal activity of a divergence neuron during a convergence step paradigm. Average firing rate with SE (gray shaded trace) is superimposed on corresponding raster plot, and average position trace with SEs is plotted below. Traces are aligned on vergence onset. $\boldsymbol{A 2}$, Linear regression between vergence angle and firing rate for divergence neurons. Regression line and data points for the example neuron shown in $\boldsymbol{A} \mathbf{1}$ are shown in black, and regression lines for the population of neurons are shown in gray. Inset, Plotting of slopes of conjugate position versus the slopes of vergence position for each individual divergence neuron. $\boldsymbol{B} 1$, Discharge rate of a convergence neuron recorded during convergence step paradigm aligned on vergence onset. B2, Linear regression between vergence angle and firing rate for convergence neurons. Example neuron regression and corresponding data points are plotted in black, and regression lines for the population of convergence neurons are plotted in gray. Inset, Plotting of slopes of conjugate position versus the slopes of vergence position for each individual convergence neuron.

population of neurons in the rSC that were linearly related to changes in vergence angle. Neurons coding slow vergence have been previously described near the oculomotor nucleus in monkey (Mays, 1984; Judge and Cumming, 1986; Zhang et al., 1991; Zhang et al., 1992). The majority of these neurons were identified dorsal and dorsolateral to the oculomotor nucleus and, similar to the neurons described in the present study, were unresponsive during conjugate saccades but either positively or negatively modulated during convergence. Judge and Cumming (1986) noted that a few of their recorded neurons were relatively more dorsal and suggested that they may have been in the pretectum or rSC. However, Judge and Cumming (1986) did not thoroughly test the responses of nearby neurons; thus, the location of these few neurons remains unknown. In the present study, we used microstimulation and single-unit techniques to establish that our population of vergence neurons were indeed in the rSC and found that, in the same area as we could evoke small staircase saccades and record the activity stereotypical rSC neurons, we also could evoke vergence eye movements and as well as record convergence and divergence neurons. Previous studies found that vergence neurons located near the oculomotor nucleus can encode vergence, accommodation, or both (Judge and Cumming 1986; Zhang et al., 1992). Although the current study was not designed to specifically test for sensitivities to accommodation, we expect that the neurons recorded in the present study would show a similar distribution of sensitivities to vergence and accommodation.

\section{The neural control of fast versus slow vergence}

One of the most striking results of the present study was the finding that vergence neurons, identified in the rSC, responded most robustly to slow changes in vergence angle. This finding is particularly interesting given what is known about the behavior of $3 \mathrm{D}$ reorienting eye movements. In particular, these movements are characterized by a period of fast saccadic vergence, which quickly redirect the eyes by unequal amounts (i.e., disconjugate saccade), in addition to periods of initial and/or late slow vergence, which are needed to binocularly position the two eyes to ensure stereopsis. 


\section{DIVERGENCE NEURON CONVERGENCE NEURON}

\section{Conjugate pursuit}
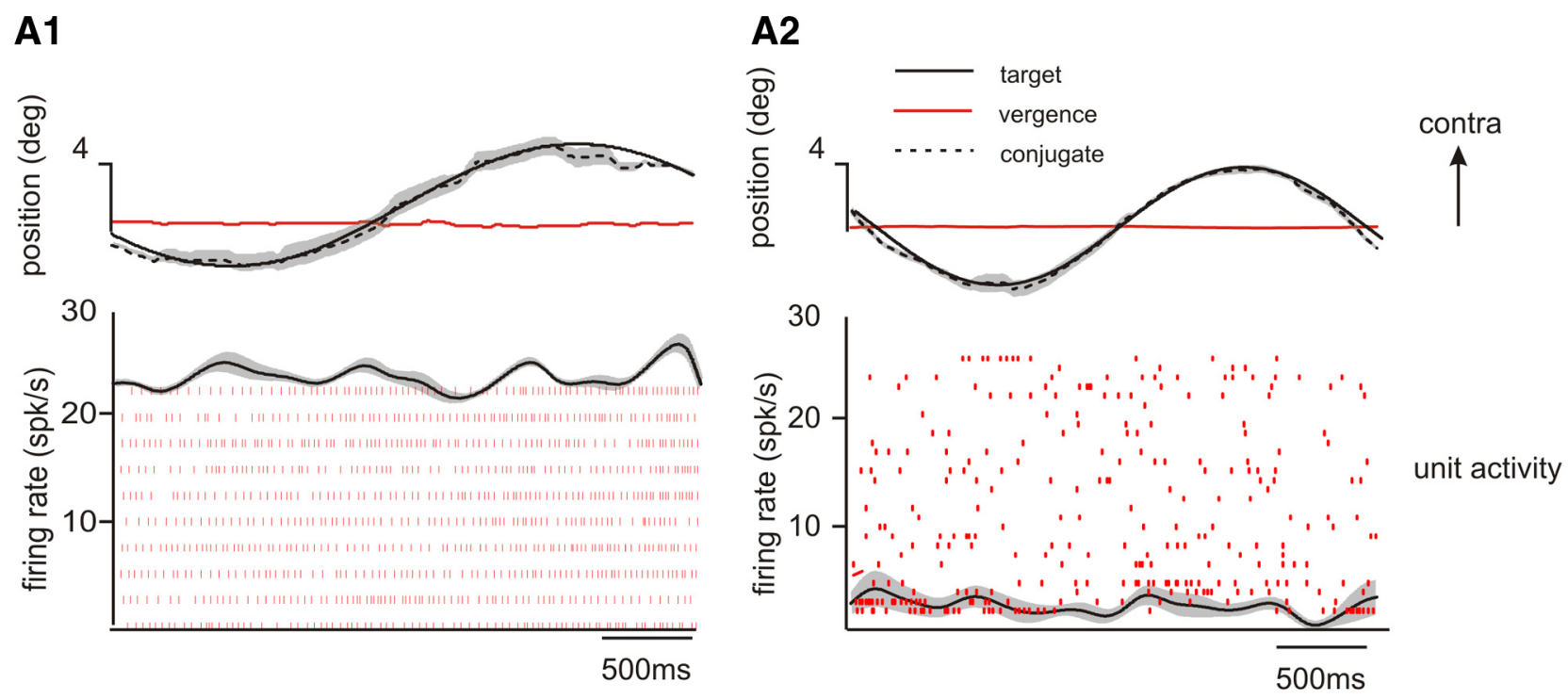

\section{Vergence pursuit}
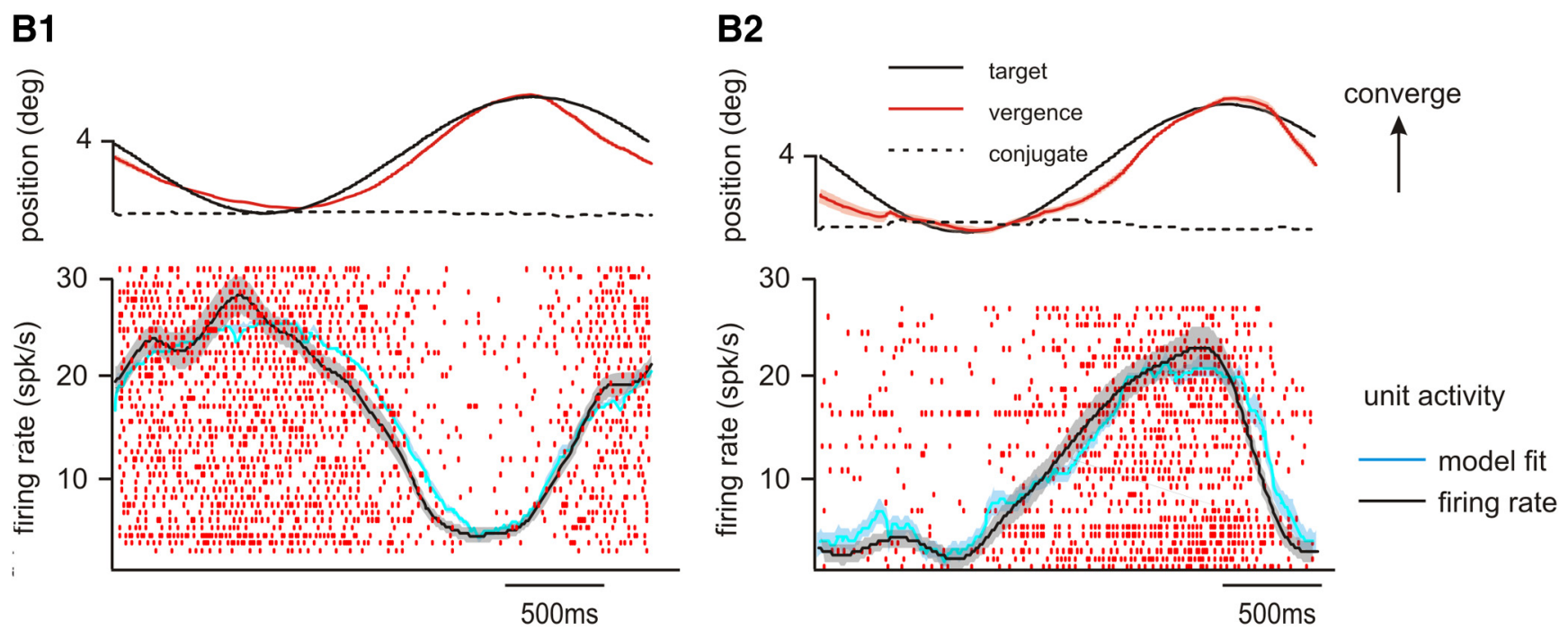

Figure 5. Neuronal activity of example vergence neurons during smooth pursuit. $\boldsymbol{A}$, Discharge rate of a divergence $(\boldsymbol{A} \mathbf{1})$ and convergence neuron $(\boldsymbol{A} \mathbf{2})$ during conjugate smooth pursuit. $\boldsymbol{B}$, Discharge rate of a divergence $(\boldsymbol{B} 1)$ and convergence neuron (B2) during vergence smooth pursuit. Model fits, estimated using Equation 1 , are superimposed in blue on the firing rate.

There are extensive data demonstrating that the discharge of brainstem premotor saccadic neurons (e.g., saccadic burst and burst-tonic neurons) is tightly linked to the onset of the disconjugate saccade and that these neurons dynamically encode integrated conjugate and vergence commands during the fast saccadic component of a 3D eye movement (Zhou and King, 1996, 1998; Sylvestre et al., 2003; Van Horn and Cullen, 2008; Van Horn et al., 2008). However, studies have also shown that saccadic neurons are silent during the slow component of a 3D gaze shift (e.g., before and after the disconjugate saccade and slow vergence tracking) (Van Horn et al., 2008).

Together, these previous results have suggested that, although the saccadic burst neurons function to rapidly redirect the eyes, an additional command is required to align the fovea of each eye on a target and ensure accurate binocular perception (King and
Zhou, 2000, 2002; Van Horn and Cullen, 2008; Van Horn et al., 2008). Additional evidence for separate fast and slow pathways for vergence eye movements resides in human lesion studies, which have shown specific deficits in fast vergence eye movements in pontine lesions (Rambold et al., 2005). Moreover, at the level of the oculomotoneurons, there is evidence that different motoneurons contribute more to certain oculomotor behaviors than others. In particular, it has been suggested that the motoneurons that project to slow, multiply innervated extraocular fibers receive their primary innervations from premotor sources involved in executing slow eye movements, whereas motoneurons that project to singly innervated extraocular fibers predominately receive saccadic premotor input (Wasicky et al., 2004; Ugolini et al., 2006).

In the present study, we have identified vergence neurons in the rSC having a very different pattern of activity compared with 


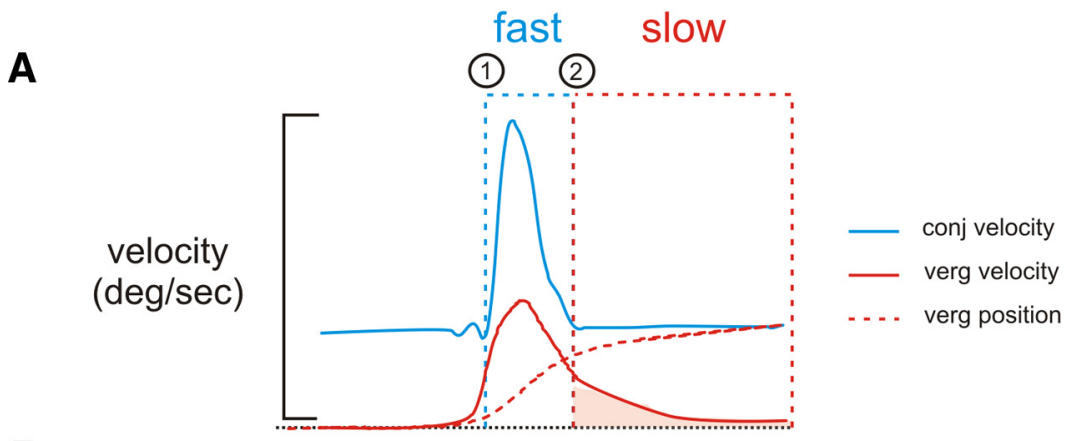

B aligned on saccade onset
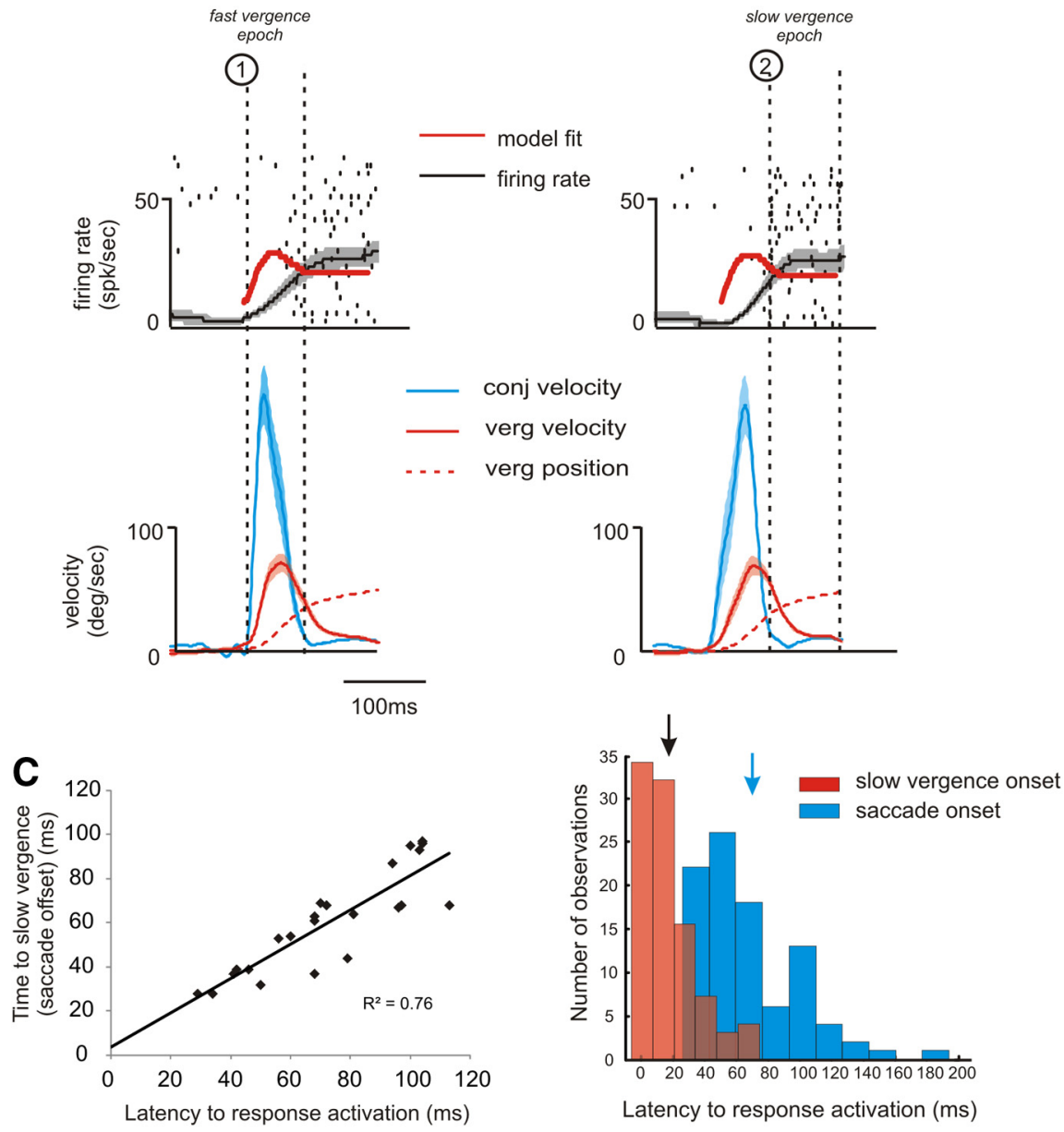

Figure 6. Neural control of fast versus slow vergence. $A$, Illustration of an example disconjugate eye movement that has a period of fast vergence to quickly redirect the eyes (blue trace) as well as a period of slow vergence to binocularly position the eyes and ensure accurate visual perception (red trace). $\boldsymbol{A} \mathbf{1}, \boldsymbol{A} \mathbf{2}$, The onset on fast versus slow vergence. $\boldsymbol{B}$, Example discharge rate of a convergence neuron during disconjugate saccades aligned on fast vergence (i.e., saccadic onset, left) and slow vergence onset (right). Average conjugate (conj, blue trace) and vergence (verg, red trace) velocity and vergence position traces are shown below the raster. Average firing rate with SE is superimposed on the raster plot. Model fit, predicted using Equation 2 is superimposed in red on the firing rate. Vertical dashed lines indicate segments used for the fits. $C$, Left, Correlation between the time of the neuronal activation and the time of slow vergence onset for the example neuron shown in $\boldsymbol{B}$. Right, Distribution of latencies calculated from the onset of neuronal activation and either the onset of the saccade (blue) or the onset of slow vergence (red) for the population of neurons.

premotor saccadic neurons. In particular, these neurons are modulated during slow vergence tracking, the onset of their activity is more correlated with the onset of slow vergence, and their activity during slow vergence can be predicted based on a model used to estimate their activity during slow vergence pursuit. Accordingly, these results suggest that vergence neu- rons in the rSC are more appropriate for encoding slow changes in vergence. In particular, we propose that a pathway from the rSC to neurons in the cMRF, which dynamically encode integrated conjugate and vergence information (Waitzman et al., 2008), to small motoneurons in the abducens contributes to slow changes in vergence.

To date, the source of fast vergence command to the brainstem saccadic burst neurons remains unknown. A likely candidate is saccade-related burst neurons of the caudal SC, which sends projections to saccadic burst neurons and receives inputs from disparity sensitive regions, including the superficial layers of the SC (Mimeault et al., 2004). Surprisingly, only one study has examined the relationship of caudal SC neurons during 3D viewing (Walton and Mays, 2003). However, although this study described a number of neurons whose discharge was clearly modulated by vergence eye movements, the investigators concluded that the $\mathrm{SC}$ was not involved in driving vergence eye movements because the movement fields did not systematically shift as predicted. Importantly, there were a number of limitations to this study that justify a reexamination of the SC for evidence of a fast vergence command signal. For example, the experimental design did not match the command generated during conjugate versus disconjugate eye movement to each specific SC neuron's optimal tuning. In the context of our present findings regarding the rSC's encoding of slow vergence, we suggest that the caudal SC should be reexamined for evidence of vergence-related information that would be suitable for shaping the discharge dynamics of upstream premotor saccadic neurons (i.e., the fast vergence command). Indeed, previous neural recordings in the caudal SC demonstrated at least three different classes of neurons: clipped, partially clipped, and unclipped cell referring to the discharge that occurred after the end of the saccade (Waitzman et al., 1991). Such "postsaccadic" discharges could be used for the control of fast or slow vergence. Unfortunately, to date, no single recording or analysis of caudal SC neurons with different postsaccadic discharges has been undertaken.

In conclusion, we propose that distinct groupings of neurons within the $\mathrm{SC}$, which encode slow versus fast vergence, underlie the ability to accurately position each of the two eyes when fixating targets in 3D space. Specifically, inputs from neurons in the rSC serve as a pathway for facilitating slow changes in vergence, whereas inputs from caudal SC could potentially mediate fast vergence. Future work is needed to test the latter proposal, as well as to fully establish how coor- 
dinated inputs from distinct fast and slow vergence pathways work together to ensure accurate gaze positioning.

\section{References}

Bergeron A, Guitton D (2000) Fixation neurons in the superior colliculus encode distance between current and desired gaze positions. Nat Neurosci 3:932-939. CrossRef Medline

Busettini C, Mays LE (2005) Saccade-vergence interactions in macaques: I. Test of the omnipause Multiply Model. J Neurophysiol 94:2295-2311. CrossRef Medline

Cherif S, Cullen KE, Galiana HL (2008) An improved method for the estimation of firing rate dynamics using an optimal digital filter. J Neurosci Methods 173:165-181. CrossRef Medline

Choi WY, Guitton D (2006) Responses of collicular fixation neurons to gaze shift perturbations in head-unrestrained monkey reveal gaze feedback control. Neuron 50:491-505. CrossRef Medline

Cullen KE, Van Horn MR (2011) The neural control of fast vs slow vergence eye movements. Eur J Neurosci 33:2147-2154. CrossRef Medline

Cullen KE, Rey CG, Guitton D, Galiana HL (1996b) The use of system identification techniques in the analysis of oculomotor burst neuron spike train dynamics. J Comput Neurosci 3:347-368. CrossRef Medline

Ferraina S, Paré M, Wurtz RH (2000) Disparity sensitivity of frontal eye field neurons. J Neurophysiol 83:625-629. Medline

Freedman EG, Stanford TR, Sparks DL (1996) Combined eye-head gaze shifts produced by electrical stimulation of the superior colliculus in rhesus monkeys. J Neurophysiol 76:927-952. Medline

Fuchs AF, Robinson DA (1966) A method for measuringhorizontal and vertical eye movement chronically in the monkey. J Appl Physiol 21:1068-1070. Medline

Gandhi NJ, Keller EL (1999) Comparison of saccades perturbed by stimulation of the rostral superior colliculus, the caudal superior colliculus, and the omnipause neuron region. J Neurophysiol 82:3236-3253. Medline

Genovesio A, Ferraina S (2004) Integration of retinal disparity and fixationdistance related signals toward an egocentric coding of distance in the posterior parietal cortex of primates. J Neurophysiol 91:2670-2684. CrossRef Medline

Gnadt JW, Beyer J (1998) Eye movements in depth: what does the monkey's parietal cortex tell the superior colliculus? Neuroreport 9:233-238. CrossRef Medline

Gnadt JW, Mays LE (1995) Neurons in monkey parietal area LIP are tuned for eye-movement parameters in three-dimensional space. J Neurophysiol 73:280-297. Medline

Goldberg ME, Wurtz RH (1972) Activity of superior colliculus in behaving monkey: I. Visual receptive fields of single neurons. J Neurophysiol 35:542-559. Medline

Hafed ZM, Krauzlis RJ (2008) Goal representations dominate superior colliculus activity during extrafoveal tracking. J Neurosci 28:9426-9439. CrossRef Medline

Hafed ZM, Goffart L, Krauzlis RJ (2009) A neural mechanism for microsaccade generation in the primate superior colliculus. Science 323:940-943. CrossRef Medline

Hayes A, Richmond BJ, Optican LM (1982) A UNIX-based multiple process system for real-time data acquisition and control. In: WESON Conference Proceedings, pp 1-10.

Judge SJ, Cumming BG (1986) Neurons in monkey midbrain with activity related to vergence eye movement and accommodation. J Neurophysiol 55:915-930. Medline

Judge SJ, Richmond BJ, Chu FC (1980) Implantation of magnetic search coils for measurement of eye position: an improved method. Vision Res 20:535-538. CrossRef Medline

King WM, Zhou W (2000) New ideas about binocular coordination of eye movements: is there a chameleon in the primate family tree? Anat Rec 261:153-161. CrossRef Medline

King WM, Zhou W (2002) Neural basis of disjunctive eye movements. Ann N Y Acad Sci 956:273-283. CrossRef Medline

Krauzlis RJ, Basso MA, Wurtz RH (1997) Shared motor error for multiple eye movements. Science 276:1693-1695. CrossRef Medline

Krauzlis RJ, Basso MA, Wurtz RH (2000) Discharge properties of neurons in the rostral superior colliculus of the monkey during smooth-pursuit eye movements. J Neurophysiol 84:876-891. Medline

Lawler KA, Cowey A (1986) The effects of pretectal and superior collicular lesions on binocular vision. Exp Brain Res 63:402-408. CrossRef Medline

Mays LE (1984) Neural control of vergence eye movements: convergence and divergence neurons in midbrain. J Neurophysiol 51:1091-1108. Medline

Melis BJ, van Gisbergen JA (1996) Short-term adaptation of electrically induced saccades in monkey superior colliculus. J Neurophysiol 76 : 1744-1758. Medline

Mimeault D, Paquet V, Molotchnikoff S, Lepore F, Guillemot JP (2004) Disparity sensitivity in the superior colliculus of the cat. Brain Res 1010: 87-94. CrossRef Medline

Munoz DP, Wurtz RH (1993) Fixation cells in monkey superior colliculus: I. Characteristics of cell discharge. J Neurophysiol 70:559-575. Medline

Ohtsuka K, Nagasaka Y (1999) Divergent axon collaterals from the rostral superior colliculus to the pretectal accommodation-related areas and the omnipause neuron area in the cat. J Comp Neurol 413:68-76. CrossRef Medline

Ohtsuka K, Maeda S, Oguri N (2002) Accommodation and convergence palsy caused by lesions in the bilateral rostral superior colliculus. Am J Ophthalmol 133:425-427. CrossRef Medline

Paul K, Gnadt JW (2006) Activity of omnipause neurons during "staircase saccades" elicited by persistent microstimulation of the superior colliculus. Vision Res 46:3430-3442. CrossRef Medline

Rambold H, Neumann G, Sander T, Helmchen C (2005) Pontine lesions may cause selective deficits of "slow" vergence eye movements. Ann N Y Acad Sci 1039:567-570. CrossRef Medline

Reyes-Puerta V, Philipp R, Lindner W, Hoffmann KP (2010) Role of the rostral superior colliculus in gaze anchoring during reach movements. J Neurophysiol 103:3153-3166. CrossRef Medline

Scudder CA, Moschovakis AK, Karabelas AB, Highstein SM (1996) Anatomy and physiology of saccadic long-lead burst neurons recorded in the alert squirrel monkey: I. Descending projections from the mesencephalon. J Neurophysiol 76:332-352. Medline

Stanford TR, Freedman EG, Sparks DL (1996) Site and parameters of microstimulation: evidence for independent effects on the properties of saccades evoked from the primate superior colliculus. J Neurophysiol 76:3360-3381. Medline

Suzuki S, Suzuki Y, Ohtsuka K (2004) Convergence eye movements evoked by microstimulation of the rostral superior colliculus in the cat. Neurosci Res 49:39-45. CrossRef Medline

Sylvestre PA, Cullen KE (1999) Quantitative analysis of abducens neuron discharge dynamics during saccadic and slow eye movements. J Neurophysiol 82:2612-2632. Medline

Sylvestre PA, Choi JT, Cullen KE (2003) Discharge dynamics of oculomotor neural integrator neurons during conjugate and disjunctive saccades and fixation. J Neurophysiol 90:739-754. CrossRef Medline

Ugolini G, Klam F, Doldan Dans M, Dubayle D, Brandi AM, Buttner-Ennever J, Graf W (2006) Horizontal eye movement networks in primates as revealed by retrograde transneuronal transfer of rabies virus: differences in monosynaptic input to "slow" and "fast" abducens motoneurons. J Comp Neurol 498:762-785. CrossRef Medline

Van Horn MR, Cullen KE (2008) Dynamic coding of vertical facilitated vergence by premotor saccadic burst neurons. J Neurophysiol 100:1967-1982. CrossRef Medline

Van Horn MR, Sylvestre PA, Cullen KE (2008) The brain stem saccadic burst generator encodes gaze in three-dimensional space. J Neurophysiol 99:2602-2616. CrossRef Medline

Van Opstal AJ, Van Gisbergen JA, Eggermont JJ (1985) Reconstruction of neural control signals for saccades based on an inverse method. Vision Res 25:789-801. CrossRef Medline

Waitzman DM, Ma TP, Optican LM, Wurtz RH (1991) Superior colliculus neurons mediate the dynamic characteristics of saccades. J Neurophysiol 66:1716-1737. Medline

Waitzman DM, Van Horn MR, Cullen KE (2008) Neuronal evidence for individual eye control in the primate cMRF. Prog Brain Res 171:143-150. CrossRef Medline

Walton MM, Mays LE (2003) Discharge of saccade-related superior colliculus neurons during saccades accompanied by vergence. J Neurophysiol 90:1124-1139. CrossRef Medline

Wasicky R, Horn AK, Buttner-Ennever JA (2004) Twitch and nontwitch motoneuron subgroups in the oculomotor nucleus of monkeys receive different afferent projections. J Comp Neurol 479:117-129. CrossRef Medline

Zhang Y, Gamlin PD, Mays LE (1991) Antidromic identification of mid- 
brain near response cells projecting to the oculomotor nucleus. Exp Brain Res 84:525-528. CrossRef Medline

Zhang Y, Mays LE, Gamlin PD (1992) Characteristics of near response cells projecting to the oculomotor nucleus. J Neurophysiol 67:944-960. Medline

Zhou W, King WM (1996) Ocular selectivity of units in oculomotor pathways. Ann N Y Acad Sci 781:724-728. CrossRef Medline
Zhou W, King WM (1998) Premotor commands encode monocular eye movements. Nature 393:692-695. CrossRef Medline

Zuber BL, Semmlow JL, Stark L (1968) Frequency characteristics of the saccadic eye movement. Biophys J 8:1288-1298. CrossRef Medline 